\title{
IMPLEMENTATION OF COLLABORATIVE TECHNOLOGIES AS A LEARNING PROCESS
}

\author{
Tatyana Bondarouk \\ Faculty of Technology \& Management \\ Human Resource Management Group \\ University of Twente \\ P.O. Box 217 \\ 7500 AE Enschede, the Netherlands \\ phone.: +31-53-4893666 \\ fax: $+31-534892159$ \\ email: t.bondarouk@sms.utwente.nl \\ Klaas Sikkel \\ Faculty of Computer Science \\ Information Systems Group \\ University of Twente \\ P.O. Box 217 \\ 7500 AE Enschede, the Netherlands \\ phone: +31-53-4894003 \\ fax: $+31-53-4892927$ \\ email: sikkel@cs.utwente.nl
}

\section{Introduction}

Implementation of technology in an organization can be regarded as a learning process and, in particular, implementation of groupware technology, as a collaborative learning process. In this chapter we propose a model of learningoriented implementation of groupware technologies. We believe that the model is useful in several ways. The model provides novel insights, highlighting issues relevant to the human aspects of implementation processes. Moreover, we envisage that is it possible to improve such processes, based on the understanding provided by our model.

With collaborative technologies we mean computer-based systems that give support for collaborative work. Systems specifically designed to do so are commonly called groupware. But with the rise of internet technologies on the one hand and integrated office environments on the other hand, the distinction between groupware and other information and communication technology gets blurred. Relevant for our perspective is not whether a system to be implemented classifies as a groupware system, but whether the technology is to be instrumental in supporting collaborative work.

Learning continually takes place at different levels, ranging from the individual to the organizational level. Characteristic for collaborative work, in which a team works as a unit in addressing a task, is that a team learning level can be distinguished. There is a body of knowledge about collaborative on-the-job learning (Marsik and Watkins, 1992; Dixon, 1994; Swieringa \& Wierdsma, 1994; Onstenk, 1995; Watkins \& 
Marsick, 1996), but by and large this is not taken up in the groupware implementation literature.

The perspective presented here is a novel one, therefore it is worthwhile to motivate our view before we present the theoretical framework. Why would we want to consider a collaborative technology implementation process as a collaborative onthe-job learning process?

- User groups adapt a novel way of working when a new technology is introduced. Not all groups do this in the same manner, and this adoption process, called appropriation (DeSanctis and Poole, 1994; Ruel, 2001) depends on the group processes. The terms in which one describes the appropriation process - sharing understanding, mutual adjustment - are closely related to learning theory.

- Changes in technology do not only allow more effective ways of doing the same work, but, in addition, lead to changes in various aspects of professional competency such as knowledge, skills, and attitudes. That, in turn, could influence on-going use of technology. Hence, in theory, there is an on-going evolutionary process of professional and technological development.

- While using collaborative technology in practical situations, user groups gradually discover the affordances provided by the system and come up with new, unforeseen ways of working. We believe that lots could be gained from collaborative technology if users exploit their group learning potential to a large extent.

- In several accounts of case studies, the implementation process did not take place in an optimal way, and the cause of this has been attributed to a lack of reflective restructuring among the users. (Tucker et al., 2001; Hettinga et al., 2001)

These arguments suggest that an appropriate collaborative learning climate in an organization could lead to better implementation of groupware. Having insights in the relevant aspects, we are able to recognize obstacles to the proper learning process and we could improve the process by eliminating, or at least diminishing these obstacles.

On a general level, an approach based on learning fits well to a systemic view. As indicated by numerous case studies (e.g. Bikson and Eveland, 1996; Orlikowski 1996), implementation of collaborative technologies does not follow a straight path that can be laid out in advance. Implementation of technology leads to perturbations in systems dependent on it, and the process is to be adapted as the implementation unfolds. Central in our approach is the group as a systemic entity. While the organizational climate and the individual users do influence the acceptance of groupware, ultimately the success of the system depends on how it is approprated by collaborating groups. We do not follow a specific systems approach, hard (Maani and Cavana, 2000) or soft (Checkland and Scholes, 1990), but in our view, our model has a lot in common with the general line of thought of systems theory.

The purpose of this chapter, in sum, is, firstly, to present our ideas about the influence of group learning on on-going use of collaborative technologies and, secondly, to propose a model, in which implementation is regarded as a learning process that takes place at different levels, reaching from the individual user to the entire organization. Our vision is presented in a descriptive model, which can be considered as a 'cognitive map' rather than a causal model. We believe that the model 
is useful because it provides novel insights, highlighting issues relevant to an evolutionary implementation process of collaborative technologies.

The chapter is structured as follows. We start with an elaboration of the theoretical background. Next, we present a model of collaborative on-the-job learning in general terms and we provide an operationalization for the model from a particular case study. Finally, we present our model of groupware implementation, in which collaborative learning is embedded in an organizational context, and we discuss the variables influencing the learning process.

\section{The learning-oriented approach to groupware implementation: theoretical framework of the study}

To compose the framework of the learning approach, we combine important and specific characteristics, extracted from three distinct areas of research. Implementation of technology is considered from an organizational and management science perspective. Computer Supported Cooperative Work is a distinct interdisciplinary research area that provides understanding of the design and use of collaborative technologies. Collaborative learning, finally, draws upon educational sciences. To introduce our theoretical basis we briefly describe each of these three domains.

\section{Implementation of technology}

Anybody writing about implementation of technology, should address the question how the author defines implementation. Gottschalk $(1999$, p.80) notes that "the term implementation is given a variety of meanings in the literature" - and we would add that in lots of IT studies implementation is mentioned as an implicitly clear word (Joshi, 1991; Orlikowski and Robey, 1991; Lederer and Salmela, 1996; Griffith, 1996; Mark and Wulf, 1999; Pipek and Wulf, 1999).

Searching for precise understanding of groupware implementation in the CSCW and MIS literature we found that some studies regard it as a linear process with a particular set of activities in order to embed new technologies in organizations. Bikson (1996, p.148) defines implementation as "the series of decisions and actions by means of which a new technology is incorporated in the day-to-day work of an organization". Some studies view implementation as a "dynamic process of mutual adaptation between the technology and its environment" (Leonard-Barton, 1988, p. 252). But incorporation of a new system into an organization, or adaptation between the system and its environment - these still seem to be vague.

To shed some light on understanding of technology implementation, we follow the proposition of Gottschalk (1999) and consider the critical point as a stage of implementation completion. In the table 1, the reviewed studies on implementation are classified in accordance to the authors' opinions on the phases of implementation completion. This table is based on the research of Gottschalk (1999), but we have added some new entries. 


\begin{tabular}{|c|c|}
\hline $\begin{array}{l}\text { Implementation is completed when } \\
\ldots\end{array}$ & Study \\
\hline $\begin{array}{l}\text { A new system (or some changes in } \\
\text { the system) is technically installed. }\end{array}$ & $\begin{array}{l}\text { Lucas, } 1981 \\
\text { Nutt, } 1986\end{array}$ \\
\hline The system is accepted by users. & $\begin{array}{l}\text { Baronas and Louis, } 1988 \\
\text { Alavi and Joachimsthaler, } 1992 \\
\text { Lou and Scamell, } 1996\end{array}$ \\
\hline The system is adapted. & $\begin{array}{l}\text { Leonard-Barton and Deschamps, } 1988 \\
\text { Orlikowski, 1992; } 1993 \\
\text { DeSanctis and Poole, } 1994 \\
\text { Volkoff and Ivey, } 1999\end{array}$ \\
\hline $\begin{array}{l}\text { Satisfaction with the system is } \\
\text { achieved. }\end{array}$ & $\begin{array}{l}\text { Griffith, } 1996 \\
\text { Klein and Sorra, } 1996\end{array}$ \\
\hline Intended objectives are met. & Lederer and Salmela, 1996 \\
\hline $\begin{array}{l}\text { There is a need for removing the } \\
\text { system or for a major change of it. }\end{array}$ & $\begin{array}{l}\text { Sanderson, } 1992 \\
\text { Pipek and Wulf, } 1999\end{array}$ \\
\hline
\end{tabular}

Table 1. Stages of implementation completion (adapted from Gottschalk, 1999).

Obvious is that implementation is a process that takes certain time until complete. And the completion stage can be and crucial issue in understanding of the implementation process, but it needs to be accurately determined.

We found descriptions of implementation in organizational studies about implementation of innovation. Klein and Sorra (1996, p.1055) pose that implementation of innovation is connected with "gaining targeted employees' appropriate and committed use of an innovation". Baronas and Louis (1988, p.113) define implementation as a "transition situation in which users experience a threat of reduced control over their work". Important is that implementation is considered not in terms of what is being introduced, but in terms of changes in behavior of targeted employees - how they appropriate an innovation.

We propose to root implementation completion of groupware in the stage when the employees start to use the system quite stable in order to perform a certain task. Routine use of technology is limited by the nature of the task: if the task is changed it may have the consequence that use of technology will be different.

We regard implementation of groupware as adoption of a system during the transition period between the initiative to get a new system and the stable use of it within a task (Bondarouk and Sikkel, 2001a). Put in other words, implementation is the critical doorway between the decision to adopt technology and the routine use of it. Usually it takes long from the idea to have a new system to introducing that to employees. If the desirable product does not exist there will be a need to design and develop that. 
The transition period includes certain actions based on the users' experience. Evolution of the implementation process ranges from non-use, or even avoidance of the system, through bored and passive exercising, - to enthusiastic, skilled and consistent use. Typically the adoption process will stabilize after some time.

'Stable use' of a system assumes the range in the adoption process when the targeted employees use the system within a certain task skillfully, actively and taskconsistently. From the learning perspective, targeted employees use technology in a stable way when they are able to learn on their own from the system how to operate in order improve their task performance further. Self-study ability assumes that users don't need any instructions and have sufficient knowledge and skills to improve their capacities in operating the system.

\section{Collaborative technologies}

Computer-Supported Cooperative Work (CSCW) emerged as an identifiable field of study in the second half of the 1980ies (Greif, 1988). Studying the role of computers in group work is an interdisciplinary effort. In order to construct systems that effectively support teamwork, knowledge is needed on how teams do work together. Studies in CSCW range from construction and experimenting with groupware system prototypes, via implementation studies in various organizations, to ethnografic studies on team work in specific settings.

Characteristic for the way of thinking in the CSCW research community is that the real nature of work is hard to capture and eludes a completely formal description. Informal work practices differ from formal work procedures. Work is situated (Suchman, 1987), what people do in order to cope with a given task depends on the situation at hand. This holds for individual work, but even more for team work, the essence of team work being that people collaborate in addressing a task. This makes $\mathrm{CSCW}$ as a research field essentially different from Human-Computer Interaction. The focus of study is not merely how users interact with groupware in order to address a task, but how a group of users collectively uses technology to achieve something. Bannon and Schmidt (1989) define CSCW as "an endeavor to understand the nature and characteristic of cooperative work with the objective of designing adequate computer technologies."

The main characteristic of collaborative work (or cooperative work; the terms are used a synonyms), is mutual dependence of the involved persons. This means that one relies positively on the quality and timeliness of the work of one's collaborators, and vice versa, resulting in positive (though not necessarily harmonious) interdependence (Schmidt and Bannon, 1992).

Because of this interdependence, collaborative work needs coordination of various kinds - to distribute and schedule the work, but also to discuss how the work is to be organized and handled. Collaborative work always involves two levels of communication: the "formal" and the "cultural". The formal level refers to communication directly related to the objects of work and the tasks at hand. On the cultural level, people interpret the work, give sense to it, express doubts, etc. (Robinson, 1991). If a system is used to mediate collaboration it is essential that is supports communication on both levels.

Systems to support collaborative work are commonly called groupware. Baecker (1993) sees groupware as any "multi-user software supporting computer-assisted 
coordinating activities". Ellis, Gibbs and Rein (1991), define groupware as "computer-based systems that support groups of people engaged in a common task or goal and that provide an interface to a shared environment". Whether email is a groupware system, hence, is a matter of definition (it satisfies only the former one). Specifically excluded are multi-user systems like time-sharing systems and databases, in which resources are shared for various reasons but the user interface carefully hides that fact that multiple users interact with the system simultaneously.

Groupware systems traditionally are classified along the dimensions time (synchronous vs. asynchronous collaboration) and space (local vs. distributed). Most types of groupware are intended to support team work in geographically distributed groups. Synchronous distributed collaboration is supported, for example, by desk-top conferencing, in which documents and applications can be shared in addition to a video connection. An example of an environment for asynchronous distributed collaboration is a "shared workspace", which may contain work objects, messages, and other information. (Bentley et al., 1997). Electronic Meeting Systems, on the other hand, are a class of groupware systems to support local collaboration. Such systems facilitate brainstorming and decision making in a meeting room in which every place is equipped with a workstation.

Until around 1995 the construction of collaborative technologies was a major technical effort. The availability of Lotus Notes and internet/intranet technologies have brought a qualitative change in the construction of groupware. Such general platforms can be extended with groupware add-ons, which take less effort to construct and - more importantly - reconstruct based on experiences in real use.

In the $21^{\text {st }}$ century, in our view, with a variety of technologies around, implementation of these technologies deserves at least as much attention as the development of new technologies. The prime aspect of interest in CSCW implementation studies is how technology is used to support collaborative work and how the implementation process can be improved to increase the effectiveness of this support. Whether the technology that is used is a groupware system or another product is relatively unimportant, as long as the technology is instrumental in the teamwork.

\section{Collaborative learning}

The concept of collaborative learning promotes our view on the social issues in adopting of groupware. We define learning as changing knowledge and behavior, and focus not on learning in general, but learning 'in the work place' (Watkins and Marsick, 1996), or on-the-job learning (Onstenk, 1995).

Swieringa \& Wierdsma (1994) distinguish conscious and unconscious on-the-job learning. Unconscious process includes formal and informal learning. Informal learning is learning by imitation: picking up other people's skills. Formal learning takes place by means of rewards and punishments (compliments; bonuses; disapproval; reprimands). Both types are very early forms of learning and based on emotions and feelings of learners.

Another type of learning is methodical, or technical, that is completely occupied with conscious learning. Methods themselves might include imitations, plays, simulations, - different known approaches. Conscious learning applies to learning via special courses or instructional materials. However, it also takes place in conversation 
with colleagues, at the work place, or during a problem-solving task. Conscious learning always leads to a higher level of performance as learners know why, what and how they learn. Moreover, they can decide whether to stop the process or continue it. There is another advantage of conscious learning: it helps to improve learning ability, or learning potential (Swieringa \& Wierdsma, 1994). Learning potential, also called meta learning, or self-education, refers to the ability to learn.

The findings from a number of studies (Watkins, 1991; Onstenk, 1995; Dixon, 1994; Crossan et al., 1999) have validated that the fundamental characteristic of learning in the work place is work socialization. It includes acquisition of the spirit of a company, norms and values of the occupation. It plays a significant role not only during first entering a company, but also during the following periods in the organization as a whole. Work socialization implies that individual learning depends upon the collaborative learning. And the converse is also true: individuals influence collaborative learning.

Socialization calls for collaboration, which includes mutual interdependence of individual and a group. Collaborative learning doesn't consist of the 'arithmetical sums' of individual learning contributions, but appears to be a more complex and integrated phenomenon. If employees work collaboratively and engaged in a common task with the use of technology, on-the-job learning gets the features of team learning.

Reflective processes are viewed as the necessarily ingredient of learning that assumes understanding oneself in a company. We refer to the concept of Marsick (1987), in which the focus is made on reflection on one's own professional experience, on decision-making and objectives. This approach emphasizes the importance of feedback, mastering particular methods and learning to learn. The focus is on problem solving and seeking improvements (Senge, 1990; Kim, 1993).

Collaborative, or group, understanding of technology seems to be something different than individual understanding of it. Collectively operating a system, reflecting on it, and making sense of the system is a different and more complicated process than the individual process of acquiring an understanding of the situation.

Understanding of the nature of technologies is related to the users' images of technology capabilities and functionality. Orlikowski and Gash (1994) have introduced the term technological frames to identify that subset of the employees' cognitive structures that concern the assumptions, expectations, and knowledge they use to understand technology in organisations (p.178). Collaborative, or shared, understanding of technology seems to be related to the concept of shared technological frames (Orlikowski and Gash, 1994). Common meaning of the system is developed in a dialogue when users share their mental models about technology. Particular opinions about why and how the system was introduced, about its basic and specific functionality, about the most effective ways of using it, - these are the issues that are shared in one collaborative unit, or group of users.

We view group learning as behavior that consists of actions carried out by team members through which a team obtains and processes data that improves cooperation (adapted from Druskat and Kayes, 2000). In other words, team learning is team interactional processes, like seeking feedback, asking for help, talking about errors, experimenting, discussing of failure, looking for information from outside, critiquing, comparing, evaluating, developing a collective vision, etc. (Edmondson, 1999; Schippers et al, 2001; Stahl, 2002). 
We describe four, in our view, basic components of team learning:

- Positive interdependence. It is supposed that we are linked with others in a way so that we cannot succeed unless they do. There are mutual benefits of the work: our colleagues' performance benefits us, and our work profits them as well. Within every co-operative learning act, it is important to stress the establishment of the group task through mutual interdependence goals.

- Individual accountability, or individual responsibility. The purpose of collaborative on-the-job learning is increasing group competence. Employees learn together so they can subsequently perform higher as individuals. At the same time individual accountability tends to eliminate "free riders" and "workhorses" (Nolinske \& Millis, 1999).

- Person-to-person promotive interaction. Employees promote each other's success by helping, advising, assisting, encouraging and supporting. Certain activities and interpersonal dynamics occur only in the case of stimulating discussions, oral explanations, formal and informal communication.

- Group maintenance (Nolinske \& Millis, 1999) is oriented on building a group capability to reflect on working together, i.e. to maintain and develop co-operative efforts. People discuss how they can improve their group activity.

After having summarized the theoretical background of collaborative on-the-job learning we'd like to spend a few more words on why we think this theory is relevant in the context of implementation of collaborative technologies.

Research in collaborative technologies focuses on collaborative work with the objective of designing adequate computer-based technologies. Hence there is a tendency to focus more on the type of interaction to be supported - which is what the technology should provide - than the semantics of the interaction on a social level. An understanding of the nature of collaboration helps to design systems the right way, but this understanding is geared towards the use of technology.

Numerous studies have shown that implementation of collaborative technologies is a process that takes time. User groups do not change their ways of working over night but gradually appropriate the available technology. In order to allow further support of such processes, a further understanding of the true nature of these processes is needed.

Collaborative learning provides a suitable theoretical foundation for such a further understanding. It fits with the insights developed so far from implementation studies of collaborative technologies and seems readily applicable. For example, consider the observation of Robinson (1991) that collaboration always involves different types of communication, with a social level distinct from the formal level. The perspective of collaborative on-the-job learning not only confirms this, but, moreover, gives insight in different aspects of interaction at the social level. The relevant concepts in implementation of collaborative technology and collaborative learning are related, and the latter can be used as an extension of the former.

In sum, the value of a learning approach in this context is that it provides us with an extension (as opposed to an alternative paradigm) to the theoretical foundation of implementation of collaborative technologies and, moreover, one which promises to give guidelines for improving implementation processes. 


\section{A model of collaborative learning as basis for groupware implementation}

The model for groupware implementation that we propose is process-based and aims at understanding the behavioral mechanism of on-going use of groupware as collaborative on-the-job learning. In this section we describe the learning process, in the next section we look at the organizational context of it and variables that influence the learning climate.

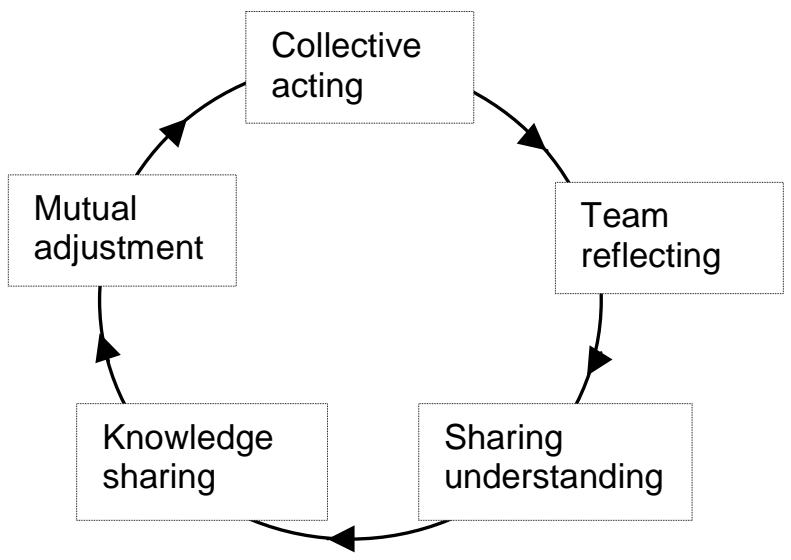

Figure 1. Collaborative learning cycle based on Kolb's (1984) experiential learning cycle

In order to build our understanding and develop a model we have transferred the experiential individual learning cycle of "acting-reflecting-thinking-deciding" (Kolb, 1984) to the collective one. On the inter-personal level, the mechanism of team learning is described with the following wheel: "collective actions - team reflection sharing understanding - knowledge sharing - mutual adjusting" (Figure 1). The team learning cycle consists of five steps (as opposed to the four steps of individual learning), for reasons that we will elaborate below.

At a group level, learning is conceptualized as on-going group interaction activities of group acting and reflecting (Edmondson, 1999). A group learning cycle begins with the collective experiences and actions, when a group of people is given a certain task to perform. According to Schippers et al. (2001), action refers to the goaldirected behaviors relevant to achieving the desired changes in team objectives, strategies.

This stage turns to the group reflection - the extent to which group members reflect upon, and communicate about the group's objectives and strategies (e.g. decision-making), and up-date them to the current circumstances (Schippers et al., 2001). Reflection takes place through a variety of activities: discussions, collective debates, presentations that aim at knowledge externalization.

The most crucial difference between individual and cooperative learning lies in the knowledge domain. When we are to transfer individual learning to cooperative one, the act of knowing becomes more complicated: people ought to share their knowledge. Some notions need to be developed of what is knowledge sharing. In a strict sense knowledge can be hardly shared. Knowledge is not something that can be passed around (Hendriks, 1999). It is also different from but related to information division (Nelson \& Cooprider, 1996). 
We agree with Hendriks (1999) that to share someone's knowledge there is a need of its reconstruction. Knowledge sharing as the process itself can be divided into, at least, two sub-phases: sharing understanding, or knowledge 'externalization' and then, sharing knowledge itself, or knowledge ‘internalization' (Hendriks, 1999).

Sharing understanding implies mutual informal acceptance and respectfulness of diverse ideas and suggestions. It can appear in many forms, including presentations, lectures, oral explanations of ideas, or 'codifying it in any intelligent knowledge system' (Hendriks, 1999). This sub-process is not necessarily conscious. For example, employees can learn by watching someone's performance, even if they are unaware of the specific knowledge needed for the task performance. But we are convinced that in almost all practical situations where knowledge sharing is going to occur it is important to stimulate 'knowledge owners' to externalize their knowledge in a way that is suitable for others. After that the wheel cycles to knowledge sharing. Knowledge sharing involves using insights to help people see their own situation better (Kim, 1993). Internalization also takes on a great variety of forms: learning by doing, reading books, etc. It is oriented to those people who look for acquisition of knowledge.

The last step in the cooperative learning is mutual adjustment. This supposes joint regulations, planning, arrangement and deciding. After planning is completed, its implementing starts that provokes a new wheel beginning with collective acting. A new learning cycle will be based on the previous group experience and knowledge. Planning can also take place during the action, or executing a task, when plans are developed and shaped by seeking feedback, group reflecting processes, that strengthens importance of group reflexivity.

It should be underlined that the division of the learning cycle in five consecutive steps is a theoretical construct. In reality, one does not observe these steps to be executed in the 'prescribed' order. A team typically engages in activities that relate to different learning steps at the same time - and there is nothing wrong with that. But in order to describe and understand the learning process in a team, it is helpful to split it into the five elementary steps.

Collaborative learning is a dynamic process that balance between two dimensions: exploration and exploitation in an organizational context. We label this as the tension between feed forward (assimilating new learning) and feed back (exploiting what has already been learnt). Through feed forward processes new knowledge and actions are developed; while feed back processes affect people on what has been known (Crossan et al., 1999).

If learning is a mechanism of on-going practice, it will run evolutionary when employees are engaged in a common task over new technology. Exercising with the new system provokes externalization of knowledge about it, then - sharing of knowledge and collective regulation of activities for the future. The use of groupware is supported by the learning mechanism (figure 2). 


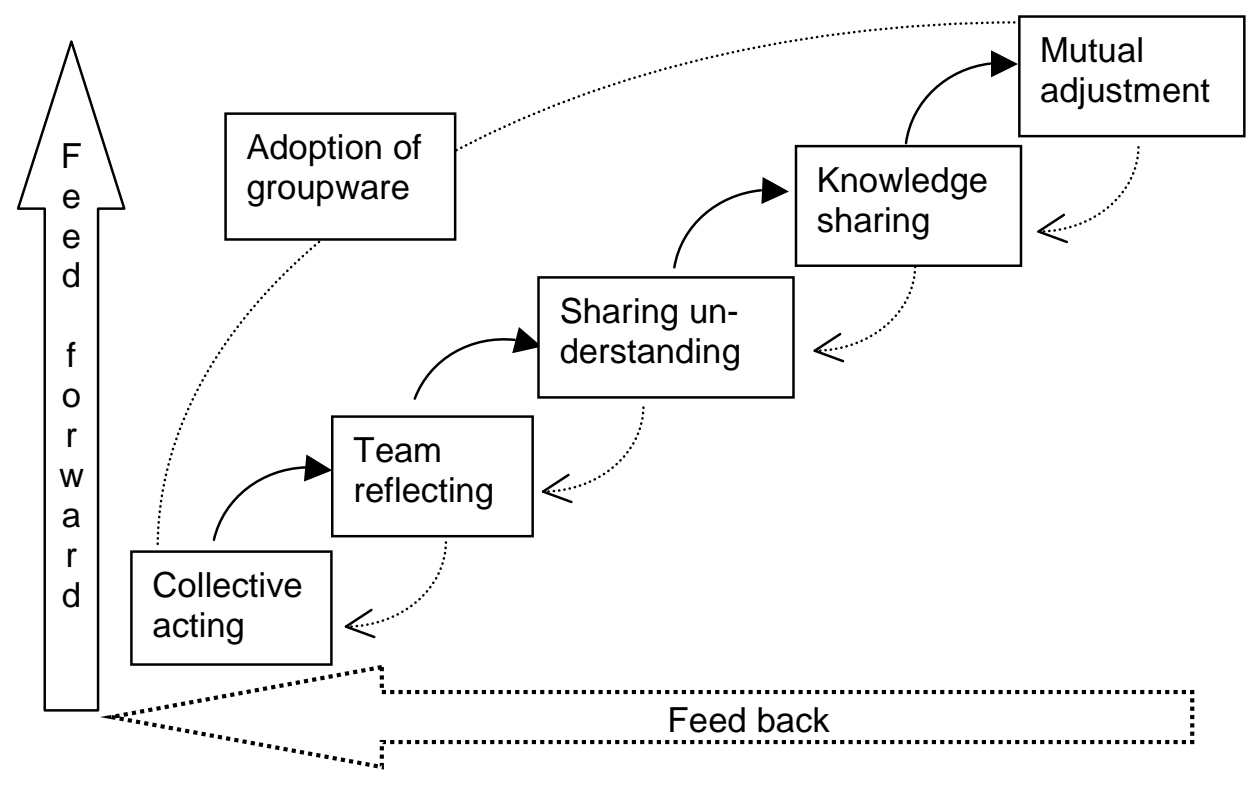

Figure 2. Collaborative learning processes

This process of learning through working using groupware technology takes place not only at the beginning, but while the system is being used.

\section{Operationalization of the model}

The five elementary steps in the team learning model are abstract concepts. In order to apply them in a given situation, the terms have to be operationalized, i.e., translated to terms and activities making sense to the persons doing the work. The operationalization may vary according to the circumstances.

In order to test the model, an explanatory case study was conducted in a local hospital in the Netherlands, where a new system was introduced six months before our research started. The system implied group work to administrate personnel information. With a qualitative approach we collected and analyzed data in order to understand group learning processes and improve the model. A detailed data collection was conducted through semi-structured interviews, observations in the field, and documents analysis.

32 interviews were employed lasting from 45 minutes to 2 hours, in total of 46 hours. Most of the interviews were individual, and also three group interviews were used because of the office environment. Some of the interviews took two meetings, as there was a need in additional clarification and information. We asked employees to describe the way a new system was introduced and group activities towards the system implementation. Postscripts of all 32 interviews were again discussed with interviewees. Analysis of data collected allowed operationalize the cooperative learning cycle regarding groupware implementation (Bondarouk and Sikkel, 2001b), see table 2 . 
Collaborative learning Activities

processes

1. Collective acting $\quad-\quad$ Replication of instructions in usual job tasks

- Searching for new techniques in a system

- Testing new procedures

2. Team reflecting $\quad-\quad$ Discovering and interpreting a problem

- Comparing with another experience

- Critiquing on-going use

3. Sharing understanding

- Demonstrating on-going use

- Asking for clarification

- Discussing errors

4. Sharing knowledge - Knowledge about intention of the system

- Recognition of functional adequacy of a system

- Comprehension of operating with the system

5. Mutual adjustment - Developing of collective vision on a problem and a way to solve it.

- Arrangements further learning activities

- Evaluating intermediate results

Table 2. Operationalization of collaborative learning in groupware implementation

\section{A systematic learning approach to groupware implementation}

After having introduced the collaborative learning model in the previous section, we will now place it in the context of groupware implementation.

The proposition is to provide a learning atmosphere systematically and study its impact in two directions: horizontal (contextual constructs, adoption of groupware, indicators of stable use) and vertical (organizational learning climate, team learning, individual learning), see Figure 3. 
Organizational
learning climate

Team

learning

Individual

learning

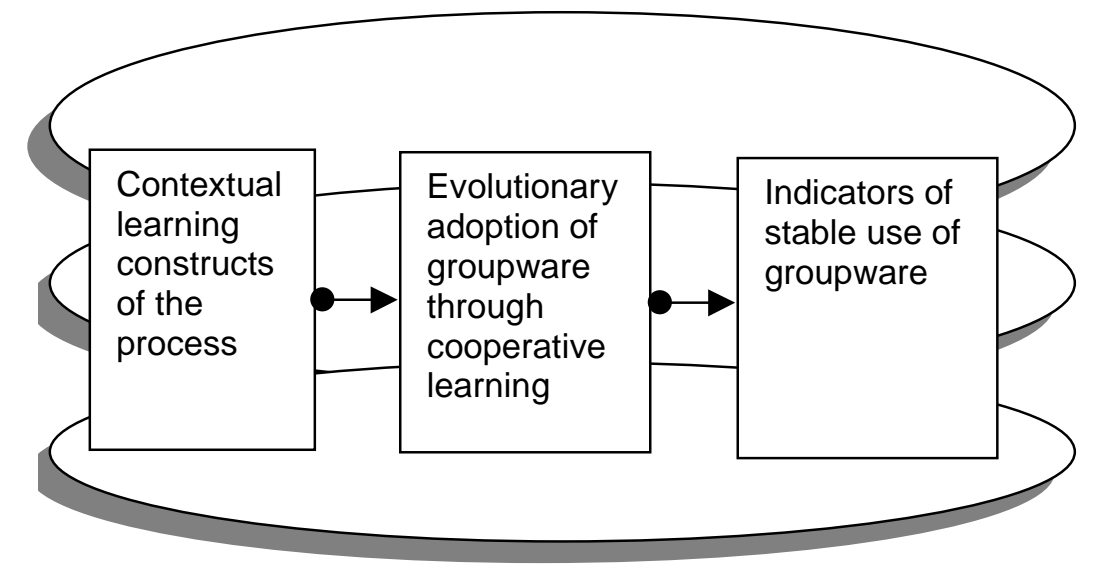

Figure 3. The systematic learning approach to groupware implementation

A body of literature shows that four contextual constructs are important and influence the process of groupware implementation (Okamuro et al., 1994; Bikson, 1996; Campion et al., 1996; Kinney and Panko, 1996; Klein and Sorra, 1996; Orlikowski, 1996; Mankin et al., 1997; Mark and Wulf, 1999; Nolinske and Millis, 1999; Pipek and Wulf, 1999; Druskat and Kayes, 2000). Each dimension consists of several items (table 3 ). 
contextual variables

1. Organizational learning climate

2. Team learning potential

3. Individual learning towards groupware implementation

\section{Items}

(a) ensuring employee skills in use of groupware

(b) encouraging use of technology

(c) promoting effective communication

(a) interpersonal understanding

(b) interdependency

(c) psychological safety

(d) pro-activity in implementation problem solving

(a) understanding of functional and technical features of technology

(b) knowledge and skills in software use

(c) attitudes about content and technical functionality of groupware

(d) involvement in the operating of groupware

(a) the role of technology in a company

(b) specification of software architecture for organizational context

(c) users' requirements

(d) enabling fruitful collaboration

(e) reliability and flexibility of technology

Table 3. Learning contextual constructs for implementation of groupware

\section{Organizational learning climate}

The discussion of this dimension is based on the management studies about organizational climate (Klein and Sorra, 1996; Schneider, 1990). Schneider (1990) defines climate as employees' "perceptions of the events, practices, and procedures and the kinds of behaviors that are rewarded, supported, and expected in a setting" (p.384). Klein and Sorra (1996) details this definition towards climate for the implementation of innovation and view it as 'employees' shared summary perceptions of the extent to which their use of a specific innovation is rewarded, supported and expected within their organization" (p.1060). It is very important to stress that climate for implementation doesn't refer to employees' satisfaction with the innovation.

In our view learning climate for technology implementation is referred to the organizational environment in which skilled, active and consistent use of technology is supported and encouraged. We have transferred the indicators given by Klein and Sorra (1996) to the interest of this study. If a company is about to implement a new technology, a strong learning climate within a company (department) may foster technology adaptation by (a) ensuring employee skills in use of groupware; (b) encouraging use of technology and disincentives for its avoidance; and (c) supporting effective user-user communication. 


\section{Group learning potential}

We define the group learning potential as a group's ability to change its behavior through acquiring and sharing knowledge and examining what is helping team performance to continually improve it.

Groupware characteristics influence the choice of variables as usually the teammates are remote while using groupware. Interpersonal understanding (Druskat and Kayes, 2000) means that teammates understand each other's concerns, preferences, tendencies, and strengths. Similar variables can be found in the literature: personal relationships (Kinney and Panko, 1996), awareness of teammates characteristics (Cannon-Bowers et al., 1995). Kinney and Panko (1996) studied 165 project teams that worked with Decision Support Systems and concluded that knowledge about teammate characteristics effectively affected interaction and allowed the teams to take advantages of member strengths.

Close to this dimension would be interdependence (Sundstrom et al., 1990; Kagan, 1993; Campion et al., 1996; Nolinske and Millis, 1999). It is supposed that we are linked with others in a way so that we cannot succeed unless they do. There are mutual benefits of the work: our colleagues' performance benefits us, and our work profits them as well. As stated in the section on theoretical background, interdependence is considered to be one of the basic traits of collaborative work.

Psychological safety is defined as 'shared belief about the consequences of interpersonal risk-taking' (Edmondson, 1999, p.375). The construct implies that the group will not embarrass, reject, or punish someone for speaking up. Edmondson (1999) identifies interpersonal trust and mutual respect as important characteristics of group safety that make teammates comfortable being themselves. Psychological safety implies willingness of all parties for open discussions, but it differs from group cohesiveness. The latter assumes 'groupthink', reducing readiness to disagree with others' views.

Pro-activity in implementation problem solving, finally, is determined as "anticipating and heading off problems through proactive investigation, assessment, and action" (Druskat and Kayes, 2000, p.333).

\section{Individual learning characteristics}

Individual learning characteristics are (a) understanding of technological features, (b) knowledge and skills in software use, (c) attitudes about content and technical functionality of groupware, and (d) active involvement in the operating of groupware.

We state that an understanding of users' interpretations of a technology is critical to realize their interactions with it. To interact with technology people have to make sense of it; and in the sense-making process they develop their understanding of the nature of technology.

There is a conflicting evidence whether prior knowledge and skills in groupware use has any effect on individual "contribution" to the process of technology adaptation. This point is implicated with the organizational learning climate: is it necessary to provide special training before implementation or to consciously "throw" the technology at users. Grudin (1994) indicates the same: the lack of training is a difficulty when introducing a new system. On the other hand, the lack of training and 
experience was not cited as barrier for the groupware implementation in the e-mail survey of 278 empirical researches (Butterfield et al., 1993).

Evident from the different conflicting findings is that prior experience and skills of the users and early investments in training may recompense, but probably there will be a need to be accompanied by careful recognition of other individual characteristics such as attitudes and active involvement in operating with groupware.

Attitudes about groupware might be "implementation barriers" if technology lags behind users' needs (Gottschalk, 1999).

\section{Technological prerequisites}

Technology-related dimensions, or technological prerequisites: (a) the role of technology in a company; (b) specification of software architecture for an organizational context, (c) users' requirements, (d) enabling of collaboration, and (e) reliability and flexibility of technology. It should be noted that the main research interest concerning technological prerequisites is not on the technical features, but on the extent to which those technical characteristics are transferred into the needs of individuals and teams.

\section{Conclusion and future work}

In this chapter we have proposed a model for implementation of collaborative technologies, which is regarded as a learning process. In fact there are learning processes at different levels, ranging from the individual to the organizational level. Specific for groupware implementation, and pivotal in the model, is learning at the team level that supports stable use of collaborative technologies.

In a collaborative learning process, five elementary steps can be distinguished collective acting, team reflecting, sharing understanding, sharing knowledge, and mutual adjustment - as elaborated above. We have operationalized these in the context of our case study research.

From the literature we have determined four main contextual variables that influence the team learning process - organizational learning climate, team learning potential, individual learning towards groupware implementation, and technological prerequisites - and discussed these in detail.

We believe that the model is useful because it provides novel insights, highlighting issues relevant to implementation processes of collaborative technologies. We conjecture that a better learning climate in an organization could lead to a more successful implementation. Ultimately, the insights derived from this perspective should lead to ways to foster the learning climate. For the near future we intend to consolidate the model by applying it to several case studies. 


\section{References}

Alavi, M., \& Joachimsthaler, E.A. (1992). Revisiting DSS Implementation Research: A Metaanalysis of the Literature and Suggestions for Researchers. MIS Quarterly, 16, 95-113.

Baecker, R.M. (Ed.) (1993). Readings in Groupware and Computer-Suppored Cooperative Work: Assisting Human-Human Collaboration. San Mateo, CA: Morgan Kaufman.

Bannon, L., \& Schmidt, K. (1989). CSCW: Four Characters in Search of a Context. In: J.M. Bowers \& S.D. Benford (eds.). Proceedings First European Conference on Computer Supported Coooperative Work (pp. 3-16). Amsterdam: North Holland.

Baronas, A.-M. K., \& Louis, M.R. (1988). Restoring a Sense of Control During Implementation: How User Involvement Leads to System Acceptance. MIS Quarterly, 12, 111-123.

Bentley, R., Appelt, W., Busbach, U., Hinrichts, E., Kerr, D., Sikkel., K., Trevor, J., \& Woetzel, G. (1997). Basic Support for Cooperative Work on the World Wide Web. International Journal on Human-Computer Studies 46, 827-846.

Bikson, T. (1996). Groupware at the World Bank. In C.U.Ciborra (Ed.), Groupware and Teamwork (pp. 145-183). Chichester, UK: John Wiley \& Sons Ltd.

Bikson, T.K. \& Eveland, J.D. (1996). Groupware Implementation: Reinvention in the Sociotechnical Frame. In M. Ackerman (Ed.), Proceedings of the ACM 1996 Conference on Computer-Supported Cooperative Work (pp. 428-437). New York, NY: ACM Press.

Bondarouk, T. \& Sikkel, K. (2001a). A learning perspective on groupware implementation. In: M. Khosrowpour (Ed.), Managing information technology in a global economy. Proceedings of the International IRMA Conference (pp. 701-703). Hershey, PA: Idea Group Publishing.

Bondarouk, T. \& Sikkel, K. (2001b). Cooperative learning in groupware implementation. In: K. Sikkel, M. Hettinga, T. Bondarouk, J.G. Schuurman (Eds.), Learning Groups - report of a workshop at the $7^{\text {th }}$ European Conference on Computer Supported Cooperative Work, Telematica Instituut, Enschede, the Netherlands (to appear).

Butterfield, J., Rathman, S., \& Whinston, A. (1993). Groupware perceptions and reality: An e-mail survey. In J.Nunamaker \& R. Sprague (Ed.), Proceedings of the Twenty-sixth Annual Hawaii International Conference on System Sciences: Vol. IV. Information systems: collaboration technology organisational systems and technology (pp. 208-217). Los Alamitos, CA: IEEE Computer Society Press.

Campion, M.A., Papper, E.M., \& Medsker, G.J. (1996). Relations Between Work Team Characteristics and Effectiveness: A Replication and Extention. Personnel Psychology, 49, 429-452.

Cannon-Bowers, J.A., Tannenbaum, S.I., Salas, E., \& Volpe, C.E. (1995). Defining competencies and establishing team training requirements. In R.A.Guzzo and E.Salas (Ed.), Team effectiveness and decision making in organisations (pp. 333-380). San Francisco: Jossey-Bass

Checkland, P. and Scholes, J. (1990). Soft Systems Methodology in Action. Chichester, UK: John Wiley \& Sons Ltd.

Crossan, M.M., Lane, H.W., \& White, R.E. (1999). An organizational learning framework: from intuition to institution. Academy of management Review, 24, 522-537.

DeSanctis, G., \& Poole, M. (1994). Capturing the Complexity in Advanced Technology Use: Adaptive Structuration Theory. Organization Science, 5, 121-147.

Dixon, N. (1994). The Organizational Learning Cycle. London: McGraw-Hill.

Druskat, V.U., \& Kayes, D.C. (2000). Learning Versus Performance in Short-Term Project Teams. Small Group Research. 31, 328-353.

Edmondson, A. (1999). Psychological safety and learning behavior in work teams. Administrative Science Quarterly, 44, 350 - 383. 
Ellis, C.A., Gibbs, S.J., \& Rein, G.L. (1991). Groupware: some Issues and Experiences. Communications of the ACM, 34(1), 38-58.

Greif, I (Ed.) (1988). Computer-Supported Cooperative Work: A Book of Readings. San Mateo, CA: Morgan Kaufman Publishers.

Gottschalk, P. (1999). Implementation predictors of strategic information systems plans. Information \& Management, 36, 77-91.

Griffith, T.L. (1996). Cognitive Elements in the Implementation of New Technology: Can Less Information Provide More Benefits? MIS Quarterly, 20, 99-110.

Grudin, J. (1994). Groupware and social dynamics: eight challenges for developers. Communications of ACM, 37(1), 92-105.

Hendriks, P. (1999). Why share knowledge? The influence of ICT on the motivation for knowledge sharing. In Knowledge and process management, 6, $91-100$.

Hettinga, M. (2000). Appropriation of teleconsultation. Manuscript submitted for publication.

Hettinga, M., Schippers, M., \& Schuurman, J.G. (2001). Invisible forces in favor of the status quo: Stimulating reflective restructuring. In: K. Sikkel, M. Hettinga, T. Bondarouk, J.G. Schuurman (Eds.), Learning Groups - report of a workshop at the $7^{\text {th }}$ European Conference on Computer Supported Cooperative Work, Telematica Instituut, Enschede, the Netherlands (to appear).

Joshi, K. (1991). A model of users' perspective on change: the case of information systems technology implementation. MIS Quarterly, 15, 229 - 242.

Kagan, S. (1993). Co-operative learning. San Clemente, CA: Kagan

Kim, D.H. (1993). The link between individual and organizational learning. In: Sloan Management Review, 35, 37-50.

Kinney,S.T., \& Panko, R.R. (1996). Project Teams: Profiles and Member Perceptions. Proceedings of the $29^{\text {th }}$ Hawaii International Conference on System Sciences.

Klein, K.J., \& Sorra, J.S. (1996). The Challenge of Innovation Implementation, Academy of Management Review, 21, 1055-1080.

Kolb, D. A. (1984). Experiential Learning. Experience as the Source of Learning and Development. Englewood Cliffs, NJ: Prentice-Hall.

Lederer, A.L., \& Salmela, H. (1996). Towards a Theory of Strategic Information Systems Planning. Journal of Strategic Information Systems, 5, 237-253.

Leonard-Barton, D. \& Deschamps, I. (1988) Managerial Influence in the Implementation of New Technology, Management Science, 34, 1252-1265.

Lou, H., \& Scamell, R.W. (1996). Acceptance of Groupware: the Relationships Among Use, Satisfaction, and Outcomes. Journal of Organizational Computing and Electronic Commerce, 6, 173-190.

Lucas, H.C. (1981). Implementation - The Key to Successful information systems. New York: Columbia University Press.

Maani, K.E., \& Cavana, R.Y. (2000). Systems Thinking and Modelling - Understanding Change and Complexity. Englewood Cliffs, NJ: Prentice Hall.

Mankin, D., Cohen, S.G., \& Bikson, T.K. (1997). Teams and Technology: Tensions in Participatory Design. Organizational Dynamics, 26, 63-76.

Mark, G., \& Wulf, V. (1999). Changing Interpersonal Communication through Groupware Use, Behaviour \& Information Technology, 18, 385-395.

Marsick, V. (1987). Learning in the workplace. London: Croom Helm.

Marsick, V., \& Watkins, K.E. (1992). Informal and Incidental Learning in the Workplace. London: Routledge.

Nelson, K.M. \& Cooprider, J.C. (1996). The contribution of shared knowledge to IS group performance. MIS Quarterly, 20, $409-429$. 
Nolinske, T., \& Millis, B. (1999). Co-operative Learning as an Approach to Pedagogy. The American Journal of Occupational Therapy, 53, 31-40.

Nunamaker, J.F., Dennis, A.R., Valacich, J.S., Vogel, D.R., \& George, J.F. (1991). Electronic Meeting Systems to Support Group Work. Communications of the ACM, 34(7), 40-61.

Nutt, P.C. (1986). Tactics of Implementation. Academy of Management Journal, 29, 230-261.

Okamura, K., Orlikowski, W.J., Fujimoto, M., \& Yates, J. (1994). Helping CSCW Applications Succeed: The Role of Mediators in the Context of Use. In R. Futura and C. Neuwirth (Eds.), Proceedings of the Conference on Computer Supported Cooperative Work (CSCW'94) (pp. 55-65). New York, NY: ACM Press.

Onstenk, J.H.A.M. (1995). Human Resources Development and On-the-job Learning. In M. Mulder, W.J. Nijhof \& R.O. Brinkerhoff (Eds.), Corporate Training for Effective Performance, Boston, MA: Kluwer Academic Publishers.

Orlikowski, W. (1992). Learning from Notes: Organizational Issues in Groupware Implementation, Proceedings of the Conference on Computer-Supported Cooperative Work (CSCW'92) (pp. 362-369). New York, NY: ACM Press.

Orlikowski, W. (1993). CASE Tools as Organizational Change: Investigating Incremental and Radical Changes in Systems Development. MIS Quarterly, 17, 309-339.

Orlikowski, W. (1996). Evolving with Notes: Organizational Change Around Groupware Technology. In C.U.Ciborra (Ed.), Groupware and Teamwork (pp. 23-59). Chichester, UK: John Wiley \& Sons Ltd.

Orlikowski, W., \& Robey, D. (1991). Information technology and the structuring of organisations. Information Systems research, 2, 143-169.

Orlikowski, W.J., \& Gash, C. (1994). Technological frames: making sense of information technology in organisations. ACM Transactions on Information Systems, 12, 174-207.

Pipek, V., \& Wulf, V. (1999). A Groupware's Life. In S. Bødker, M. Kyng, \& K.Schmidt (Eds.), Proceedings of the Sixth European Conference on Computer-Supported Cooperative Work (pp. 199-218). Dordrecht, the Netherlands: Kluwer Academic Publishers.

Robey, D., Boudreau, \& M.-C., Rose, G.M. (2000). Information technology and organizational learning: a review and assessment of research. Accounting Management and Information Technologies, 10, 125-155.

Robinson, M. (1991). Double-Level Languages and Co-operative Working. Artificial Intelligence and Society, 5, 34-60.

Ruel, H.J.M., (2001). The non-technical side of office technology; managing the clarity of the spirit and the appropriation of office technology. Ph.D. Thesis. Enschede, the Netherlands: Twente University Press

Sanderson, D. (1992). The CSCW implementation process: an interpretative model and case study of the implementation of a videoconference system. In Proceedings of the Conference on Computer Supported Cooperative Work (CSCW'1992) (pp. 370-377). New York, NY: ACM Press.

Schippers, M. C., Den Hartog, D. N., \& Koopman, P. L. (2001). Reflexivity in teams: The relation with trust, group potency, team leadership, and performance in work teams. Paper presented at the Academy of Management, 3-8 August, Washington DC.

Schmidt, K., \& Bannon, L. (1992). Taking CSCW Seriously - Supporting Articulation Work. Computer Supported Collaborative Work, 1, 7-40.

Schneider, B. (1990). The climate for service: an application of the climate construct. In: B.Schneider (Ed.), Organisational climate and culture, (p. 383-412). San Fransisco: Jossey-Bass.

Senge, P. (1990). The fifth discipline: The art and practice of the learning organisation. New York: Doubleday/Currency. 
Stahl, G. (2002). Contributions to a theoretical framework for CSCL. Manuscript submitted for publication.

Suchman, L. (1987). Plans and Situated Actions. The Problem of Human-Machine Communication. Cambridge, UK: Cambridge University Press.

Sundstrom, E., Meuse, K.P. De, \& Futrel, D. (1990). Work teams. In: American Psychologist, $45,120-133$.

Swieringa, J. \& Wierdsma, A. (1994), Becoming a Learning Organization, Addison-Wesley Publishing,

Tucker, A.L., Edmondson, A.C., \& Spear, S. (2001). When problem solving prevents organizational Learning. Harvard Business School working paper 01-073.

Volkoff, O. \& Ivey (1999). Using the Structurational Model of Technology to Analyse an ERP Implementation. Proceedings of the Fifth Americas Conference on Information Systems, Milwaukee, WI, August 1999 (pp. 235-237).

Watkins, K. \& Marsick, V. (Eds.) (1996). Creating the Learning Organization. Alexandria, VA: ASTD. 